\title{
Management perceptions of a higher educational brand for the attraction of talented academic staff
}

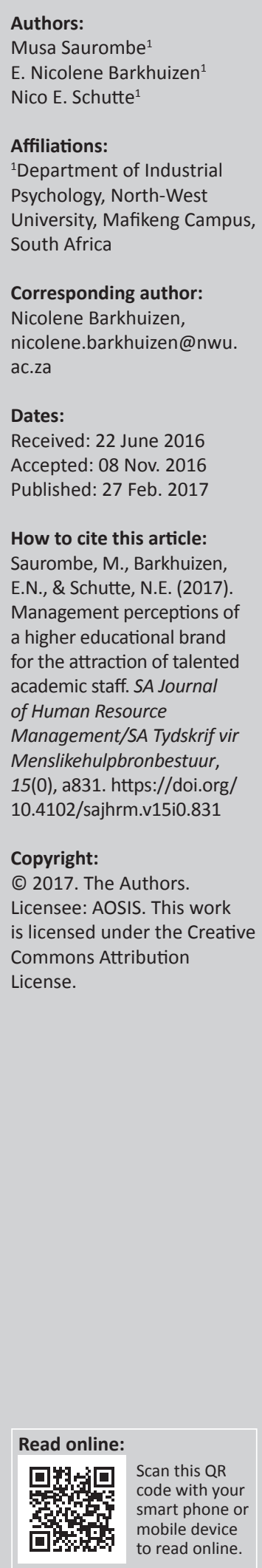

Orientation: Academic staff members have a crucial role in the success of higher education institutions (HEIs). Therefore, it is imperative to cultivate an appealing organisational brand that will attract them to HEIs as an employer of choice.

Research purpose: The main objective of this study was to explore management perceptions on a higher educational institution as a brand for the attraction of talented academic staff.

Motivation for the study: Although a substantial amount of research has been conducted on organisational branding, not much has emphasised the higher educational sector.

Research approach, design and method: A qualitative research approach was adopted, using semi-structured interviews to collect data from management $(N=12)$ of a merged South African HEI.

Main findings: The findings revealed six themes that should form the core of a higher educational brand for academic staff: reputation and image, organisational culture and identity, strategic vision, corporate social responsibility and work and surrounding environment.

Practical/managerial implications: The findings of the study will assist higher education management to create a compelling organisational brand and work environment to attract and retain talented academic staff members.

Contribution/value-add: This research makes a valuable contribution towards creating new knowledge in the key that should form part of an appealing higher education brand that will attract and retain current and future talent.

\section{Introduction}

More recently, diminishing global boundaries and technological modifications have deepened the importance of the organisational branding of higher education (Harsha \& Shah, 2011). Branding of higher education institutions (HEIs) originates from the transference of noble practises from the private business arena into the arena of academia (Wæraas \& Solbakk, 2009). Harsha and Shah (2011) postulate that the supremacy of a higher educational brand is signified by the judgements, outlooks, opinions, images and experiences associated with the brand in the minds of citizens or audiences and what these consumers have learnt, felt, observed and heard concerning HEIs over time. The internationalisation of HE has further contributed towards the advent of global university rankings (Stolz, Hendel \& Horn, 2010), which are reflective of institutional brand reputation and performance (Williams \& Van Dyke, 2008). Hence, it has become increasingly imperative for top management of HEIs to divulge the vision, mission, strategy and reason for existence of institutions to the rest of the institutional operational levels in the most effective way possible (Balmer, 2012).

According to Biraghi and Gambetti (2015), organisational branding is a continuous strategic process that mirrors the efforts of top managers to capture the identity of organisations and express it in a dependable and attractive manner to promote the organisational identification and support of stakeholders. Flake (2015) maintains that hardly any assets are as crucial to the accomplishment of organisations as the image they portray to the media, customers, shareholders as well as the general public. Moreover organisational branding epitomises one of the most treasured resources which companies possess to successfully differentiate themselves within the competitive field (Biraghi \& Gambetti, 2015). Amzat (2015) explains that branding is important for the sustainability of HEIs and the offering of products that are superior to their competitors. Therefore, HEIs should attract qualified academic staff who can ensure sustainability and quality over the long term (Makondo, 2014; Pienaar \& Bester, 2008). 
Finding highly qualified and a potential pool of talented scholars remains a central management challenge in the 21st century. Universities in sub-Saharan Africa continue to operate under conditions are seriously under-resourced, which poses significant challenges for the scholars concerned (Onah \& Anikwe, 2016; Selesho \& Naile, 2014). Employment equity and remuneration practices are important factors in attraction and retention of new academics, especially from historically disadvantaged groups in South Africa (Mapesela \& Strydom, 2005). However, the organisational brand of academic institutions continues to be hindered by unattractive remuneration practices (Makondo, 2014) and a lack of adequate incentives for knowledge production (Wangenge-Ouma, Lutomiah \& Langa, 2015).

The main objective of this study was to explore management perceptions on a higher educational institution as a brand for the attraction of talent academic staff. More specifically, this research addressed the following research questions:

- What are higher educational managers' perceptions of the current state of the organisational branding of a merged HEI?

- What are the components of a compelling higher educational brand to manage academic talent effectively?

This research is motivated from the fact that regardless of the largely renowned significance of organisational branding as a way of gaining competitive advantage, organisational branding studies suffer from vastly disjointed standpoints that makes it challenging to recognise the value of organisational branding in channel its practises (Biraghi \& Gambetti, 2015). This article explores the concept of organisational branding as it relates to higher education by breaking it down into six concise components, namely reputation, organisational culture, strategic vision, organisational identity, intended image(s) and construed image that each directly pertains to the overall concept of organisational branding. The factors that affect organisational branding are discussed consecutively in the sections that follow.

\section{Literature review}

\section{Factors affecting the organisational branding of higher education institutions}

\section{Reputation}

Organisational reputation is frequently considered as how decent, revered, appreciated and/or esteemed organisations are (Dowling \& Moran, 2012). These traits result in organisations gaining trust, which consequently aids people to believe in the organisations' reliability, talents and strategies for the future (Covey \& Merrill, 2006). In this manner, a good reputation becomes advantageous by enhancing the credibility of service providers and the trust of consumers, thus diminishing risk and related transaction charges (Dowling \& Moran, 2012). Therefore, companies should put more effort into reputation-growing activities directed at consumers and employees that focus more on non-monetary facets of reputation, comprising the enhancement of product and service quality, the fostering of an attractive workplace environment and participating in social responsibility activities (Raithel \& Schwaiger, 2015). Noble organisational reputations do not only hold the likelihood for value formation but also make it difficult for other organisations to imitate because of the impalpable nature of the reputation of organisations (Terblanche, 2015).

Studies of academics depict that their mobility choices are mostly kindled by the reputation of host HEIs, the research resources at their disposal and the compatibility between the job post and their research preferences (Agarwal \& Ohyama, 2013; De Grip, Fouarge \& Sauermann, 2010; Ivancheva \& Gourova, 2011). Williams and Omar (2014) argue that the running and effectiveness of HEIs are vastly associated with the quest for prestige or reputation. Alessandri, Yang and Kinsey (2006) highlight three scopes of the reputation of universities: the quality of academic enactment, the quality of external enactment and emotional engagement. Brewer and Zhao (2010) reference five essentials encompassing the summative reputation of universities, specifically: leadership, teaching, research, service and equity.

\section{Organisational culture}

Organisational culture is an essential characteristic of the management of organisations formed by organisations' morals, customs, fundamental assumptions, outlooks, traditions, chronicles and cyphers - including dogmata and practises (Pauzuoliene \& Mauriciene, 2012). According to Kuh and Whitt (2000), university culture is a specific type of organisational culture, which is described as the cooperative and mutually influencing arrangements of customs, values, practises, dogmata and assumptions that govern the conduct of individuals and groups in HEIs and offer a frame of reference within which to construe the importance of proceedings and activities on and off campuses. For the purpose of this article, organisational culture is defined as a system of interacting associations between fundamental assumptions, values, opinions, sacraments, the past, customs and symbols that are conveyed within all organisational management roles (Pauzuoliene \& Mauriciene, 2012).

A study by Naidoo (2013) established that genuine and longlasting academic quality would most probably occur within universities when the enablement and transformation roles reinforce collegiate and revolutionary cultures. Numerous universities in South Africa are trying to create a new and common institutional culture (Bitzer, 2009). This may necessitate that institutional culture be disintegrated to give rise to the reconstruction of a fresh culture. One has to bear in mind that institutions comprise several cultures and an assortment of institutional cultures. Consequently, the reconstruction of new culture(s) is evidently a major contest (Bitzer, 2009).

\section{Strategic vision}

According to Balmer, Stuart and Greyser (2009), the strategic vision of organisations denotes the ideal strategic 
(future-focused) standing of organisations within a set period of time. Balmer et al. (2009) further states that the strategic vision is determined after organisational aptitudes, possessions, other rival organisations as well as variations in the political, economic, moral, social and technological atmosphere have been dissected and analysed. Healthy schools, as part of best practice, monitor their policy making via strategic plans (Walker, 2011). Acknowledging the effect such plans have on the strategic guidelines of schools, Henry Mintzberg (as cited in Walker, 2011) cautions what must be at the heart of these plans: While undoubtedly not extinct, strategic planning fell from its platform a while ago, owing to the fact that planning frequently interrupts strategic thinking, triggering confusion in managers between the actual vision and the manipulation of figures. This confusion lies at the root of the issue, which is that the most efficacious strategies are in the form of visions, as opposed to plans.

Özdem (2011) opines that a sound vision statement should accentuate an inimitable feature of organisations that distinguish them from others. Their vision should be comprehended and internalised by all parties with specific interest in organisations (Özdem, 2011). Mayfield, Mayfield and Sharbrough (2015) agree that such a vision requires appropriate communication by top leadership. A strategic vision and associated moral messages depict benevolence and esteem for the parties involved and pursue the advancement of the well-being of these stakeholders (Mayfield et al., 2015).

\section{Organisational identity}

Jansen and Roodt (2014) express that organisational identity is frequently mistaken for other constructs associated with it, like organisational identification, organisational membership and organisational obligation. Lane and Scott (2007) describe organisational identity as the qualities or traits of an organisation that comprise principles, aims and operations, as well as metaphors of the organisation or its affiliates. Whetten (2006, p. 221) reiterates Albert and Whetten's description of one of the components of organisational identity as the intricate viewpoints of members concerning the question 'Who are we as an organisation?'

Martin, Burke and Cooper (2011) express that some features of an organisation's identity are long-lasting, for instance, its history, the products and services it provides and the country from which it originated. However, whether for instance a company is viewed as honourable can vary in the opinion of its employees and other involved parties. Numerous HEIs recognise their position as pertaining to their conventional two-fold undertakings of teaching and research both at the undergraduate and the graduate stages, but seem not to fully understand their role as a supplier of enduring learning in an extensive dimension, with services targeted towards adult scholars (Huisman \& Pausits, 2010). In addition, the market rivalry for continued education is mounting. This trend is compelling universities to reconsider their programmes, to carry out market assessments and determine strategic positioning and also to develop basic processes such as postgraduate curriculums or services for adult scholars (Huisman \& Pausits, 2010).

\section{Intended image(s)}

According to Balmer et al. (2009), the intended image of an organisation is the desirable or aspirational future standing of the organisation. It exists within the hearts and minds of organisational governors: it is what they foresee the identity of the organisation to be like in a specific period of time. Hugo-Burrows (1993) believes that management choices regulate the extent to which the desired organisational image is translated into strategies and policies that are directed at presenting the incorporated organisational image to the main stakeholder categories. Podnar (2014) expresses that it is extremely challenging to construct an appropriate programme to convey the sought-after organisational image if the leadership does not comprehend who the organisation is, what the vision is and what its forthcoming intentions are.

Dolphin and Reed (2011) acknowledge that organisations long for a positive attitude from significant stakeholders in the same way that organisations desire an amplified opinion of their purpose and culture. These sought-after perceptions are concentrated on helping to secure a definite foundation for the commercial association between companies and their communities (Dolphin \& Reed, 2011). A study piloted by Wood and Somerville (2008) discovered that when staff deliberated on a desired image for a University College, for instance, discussions leaned towards what they thought should be accomplished over the ensuing 10 years and how a specific corporate positioning could result in success, as opposed to becoming caught up on favourite colours and preferred typeface. The Nelson Mandela Metropolitan Business School had the vision to grow into the most desirable business school in South Africa and encouraged the decision to acquaint itself with the image of hard work, honour and authenticity of the country's first black Head of State (Opoku, Abratt \& Pitt, 2006).

\section{Construed image}

According to Balmer et al. (2009), the construed image of organisations relates to the images and reputations of the organisations adopted by customers and various stakeholder groups. Helm, Liehr-Gobbers and Storck (2011) describe the construed image of organisations as the impression organisations have about what others think of them. The Higher Education Ranking Schemes, for example, has created the notion of a world university market, which is extremely influential on all stakeholders within the knowledge service business (Tofallis, 2012).

Dolphin and Reed (2011) state that construed images are necessary because companies consider reputations not merely as treasured assets but also as replications of themselves in the institutional mirror. Construed image is an essential component in the formation of identity, which is founded on identification and differentiation procedures 
(Cian \& Cervai, 2014). The views held by members of organisations about what external parties think of their particular organisation can impact the perceptive identification of organisations and their sentiments, including their appraisals of their self-esteem (Cian \& Cervai, 2014). Dolphin and Reed (2011) also agree that construed images could be a principal instrument through which companies foresee the shifting expectations in their institutional atmospheres.

In conclusion, literature seems to reveal that the extent to which members can relate to organisations is contingent upon how they think organisations are perceived by others (construed image) and indirectly by how others perceive organisations in reality (corporate image). Therefore, the perception of outside parties in reality impacts how members believe organisations are viewed by others, which consequently impacts the identity of organisations. In light of this knowledge, the researcher interviewed the management employees of the merged South African HEI to determine what type of organisational brand they perceive is reflected to the stakeholders of the institution, particularly the academic staff members of the institution.

\section{Research design Research approach}

A research approach describes the strategies and the processes followed for research from the stage of wide suppositions to meticulous techniques of data gathering, analysis and interpretation. The choice of a research approach is further determined by the nature or essence of the research problem that is under investigation, the understanding of the researcher as well as the people that the study affects or intends to reach out to (Creswell, 2014). A qualitative approach was adopted in this study. This was motivated by the fact that the population of individuals in managerial positions within the institution is relatively small; therefore, a qualitative inquiry was considered to be more practical and pertinent.

The nature of the study also necessitated a qualitative approach because an organisational branding is fostered by employers and directed towards employees as one of the stakeholders. In terms of this study, the organisational branding is fostered by the management of the HEI and directed towards its academic staff members. Therefore, the researcher found it incumbent to obtain the detailed views or perceptions on organisational branding of the management of the merged South African HEI through qualitative inquiry in the form of interviews.

\section{Research strategy}

This research followed a case study strategy, as it was considered best suited to the researcher's goal to investigate a current phenomenon in a real-life situation (Bryman \& Bell, 2015). The themes were extracted from the semi-structured interviews and confirmed by scrutinising the worldwide body of existing literature. Qualitative case study approach in this research falls within the interpretive/constructivist paradigm (Yin, 2012). In this instance, the ontological belief is that reality is local and specifically constructed.

\section{Research setting}

The research setting in this study included a sample comprising 12 managers of a merged South African HEI. Most of the participants were interviewed in person in their offices. In cases where the researcher could not travel to areas that were not within reasonably close proximity, the researcher made use of virtual interviewing methods such as telephonic and Skype conversations for greater convenience. The researchers obtained the approval of the participants when virtual interviewing was used.

\section{Research method}

\section{Entrée and establishing researcher roles}

Permission to carry out this research was sought and obtained from the relevant authorities of the institution by means of a letter of request prior to the collection of data. Upon obtaining permission, the researchers approached interview candidates personally and requested interviews. The participants were required to give consent before answering any of the researchers' questions. Anonymity was upheld and all information provided remained confidential in adherence to the code of ethics. Ethical clearance was obtained prior to the execution of the study.

\section{Sampling}

The participants of the study included the management of a merged South African Higher Education Institution. The participants were chosen based on their work experience in higher education and their role in the organisational brand of the institution. The research participants were interviewed one after the other until data saturation was reached. This study made use of purposive convenience sampling, meaning the participants were selected based on their willingness and availability to take part in the data collection process and the relevance of their contributions. Twelve individuals in managerial positions participated in this study through interviews. Table 1 shows the demographic delineation.

As can be seen from Table 1, the majority of the participants were men, making up $58.33 \%$ (seven participants) of the sample. The demographic distribution constituted more black or African people in the sample (58.33\% - seven participants). All participants were in possession of a doctoral degree. The distribution in terms of managerial levels showed $41.67 \%$ (five participants) to be in the executive tier of management, another $41.67 \%$ (five participants) to be in the senior tier of management and $16.67 \%$ (two participants) to be in the middle tier of management. Only one out of the five participants in executive management is woman, that is, $8.33 \%$ of the entire sample as opposed to a clobbering $33.33 \%$ of men in the entire sample who held executive managerial positions. 
TABLE 1: Sample demographics.

\begin{tabular}{|c|c|c|c|c|}
\hline Participants & Gender & Race & Qualification & Job level \\
\hline 1 & Male & Black or African & Doctoral degree & Executive management \\
\hline 2 & Male & Black or African & Doctoral degree & Senior management \\
\hline 3 & Male & Black or African & Doctoral degree & Executive management \\
\hline 4 & Female & White & Doctoral degree & Senior management \\
\hline 5 & Male & Black or African & Doctoral degree & Executive management \\
\hline 6 & Female & Black or African & Doctoral degree & Senior management \\
\hline 7 & Female & White & Doctoral degree & Senior management \\
\hline 8 & Male & White & Doctoral degree & Executive management \\
\hline 9 & Female & White & Doctoral degree & Middle management \\
\hline 10 & Male & Black or African & Doctoral degree & Middle management \\
\hline 11 & Female & Black or African & Doctoral degree & Executive management \\
\hline 12 & Male & White & Doctoral degree & Senior management \\
\hline
\end{tabular}

At senior management level, three out of the five participants were women, that is, $25.00 \%$ of the entire sample, as opposed to $16.67 \%$ of men in the entire sample of the participants who hold senior management positions. One out of two participants are in middle management, that is, $8.33 \%$ of the men represented in middle management participants and the women represented in middle management participants in the aggregate sample.

\section{Data collection method}

The qualitative data collection was conducted by the use of semi-structured interviews. The purpose of the interviews was to divulge more profound meanings by allowing for new information and concepts to emerge from the results, which the quantitative data would not have managed to reveal. The interview sessions managed to specifically unravel the perceptions that management have concerning organisational branding within the merged South African HEI. The HEI management interview participants were requested to delineate their experiences where organisational branding is concerned - in line with this framework. The questions sought to determine the current organisational branding of the merged South African HEI.

\section{Recording of data}

The researcher deemed it fit to capture audio recordings of the participants' answers so that these responses could be transcribed as the data were gradually obtained because of the large volume of data that were gained as a result of a qualitative study. The audio recordings were played back and verbatim transcriptions of the data were made in a Microsoft Word document for analysis once all the data had been gathered.

\section{Data analysis}

In accordance with Bernard and Ryan (2010), a process known as transcription was used, whereby the audiorecorded responses of the participants were converted into text in a Word document. Thematic analysis was used in this study to uncover the associations that existed across the phenomena and how these associations relate with the aggregate cultural setting of this research (Leech \& Onwuegbuzie, 2008). The researcher attached mnemonic labels to each theme and sub-theme through open coding to provide a description of the newly discovered phenomena as well as inclusion and exclusion criteria. The generated codes were then refined through axial coding and the labels and their descriptions were supported by verbatim quotes from the interview responses and also compared with literature and similar studies in order to determine the validity of the data and ensure that the main research question was appropriately addressed (Leech \& Onwuegbuzie, 2008).

\section{Ensuring the quality and rigour of the research}

In line with Sargeant (2012), the following strategies were used to ensure the quality and rigour of the research:

- Being cautious of individual biases, which may have affected the findings.

- Recognising and evading prejudices in sampling and continuous consideration of techniques to guarantee adequate profundity and significance of data gathering and the analysis thereof.

- Keeping a thorough record, showing all the methods employed for the analysis of data and making sure that the explanations of data are reliable and apparent.

- Adding a significant volume of verbatim participant explanations to back the findings.

- Validating findings by requesting the participants to offer remarks concerning the interview transcripts to determine if the ultimate themes constructed significantly represent the concepts being examined.

- Taking into account the nature of the subject under investigation, to select the right method for addressing research questions, for example, individual interviews as opposed to focus groups tend to cater more for issues that are sensitive.

\section{Reporting}

The findings of this research have been tabulated, displaying the themes and various sub-themes that emerged from this study. The themes and sub-themes are substantiated by verbatim quotes obtained from the participants' answers provided during interviewing. This was done in accordance with the contemporary qualitative research approach, which entails the validating or supporting knowledge of the assumptions made in particular research settings (Bowen, 2009). 


\section{Findings}

Table 2 depicts the frequency of the themes that arose from the interviews with management. The findings in Table 2 show that work and the surrounding environment, reputation and image and organisational culture and identity were the most frequently occurring sub-themes.

\section{Theme: Organisational branding}

The sub-theme of work and surrounding environment under organisational branding occurred most frequently in this research (mentioned 28 times). Other themes that arose in descending order of frequency were reputation and image, organisational culture and identity, corporate social responsibility, merger implications as well as strategic vision.

\section{Sub-theme: Work and surrounding environment}

The sub-theme of work and surrounding environment occurred most frequently in this research. The participants were of the opinion that a working environment that enables academic staff members to perform is imperative to ensure that they stay ahead as an institution of higher learning as described by the following participant:

Then of course the most important thing is the environment which I would say is our competitive edge, to ensure that we provide a conducive environment for an academic to develop themselves because in an academic situation, an academic career is highly competitive. (Participant 1, male, executive management, doctoral degree, black or African)

In addition, another participant mentioned that:

Firstly, we provide a local environment that is conducive for focused work that is, research and teaching and learning. Secondly an enabling environment is important. If an academic needs time and flexibility, they can get it. So enabling in the sense that if I need money to go and do research, even apparatus, with the possibility of travelling to do interviews etc., then it must be available, also enabling in the sense of allowing an academic to network. (Participant 8, male, executive management, doctoral degree, white)

The participants believe that it is important for academic staff members to express what is important to them so that management can create the necessary environment and conditions for them to develop and thrive in their work as indicated by participants 5 and 11:

You must have a plan on what you want to do, and to achieve that plan, the employer gives the enabling environment to achieve that plan and you need to put something down to see

TABLE 2: Frequency of themes.

\begin{tabular}{lc}
\hline Theme and sub-themes & Frequency \\
\hline Organisational branding & 72 \\
Reputation and image & 14 \\
Organisational culture and identity & 13 \\
Strategic vision & 5 \\
Corporate social responsibility & 12 \\
Work and surrounding environment & 28 \\
\hline
\end{tabular}

what you can do. (Participant 5, male, executive management, doctoral degree, black or African)

And:

We provide a very conducive environment for one to study. If you're at this campus, as a lecturer, and you're not studying, you've got to account to me. (Participant 11, female, executive management, doctoral degree, black or African)

The participants also explained that an attractive external environment in terms of the geographic location of an institution is also imperative in influencing the decision of academic staff members to attend the institution as expressed by the following participants:

Another thing is that the environment also plays a very big role. A university in a rural environment finds it most of the time difficult to attract very top people into the place. They will tell you about distance, they will tell you about proximity to a good school, English school and all those kinds of things. They will tell you about proximity to the airport, we have an airport here but it wasn't functioning for some time. (Participant 5, male, executive management, doctoral degree, black or African)

Another participant also felt that working in such an environment as where their campus is situated is an advantage and that it has an element of attractiveness by mentioning that:

You can see that generally it's located in a rural place, you know, if you look at the cost or the nature of the standard of living when you compare it with a very busy city like Cape Town, Pretoria or Jo'burg, you'll see that, and I think I'm also talking based on why I considered coming here, you'll see that life is not that very expensive in an environment like this. (Participant 10, male, middle management, doctoral degree, black or African)

\section{Sub-theme: Reputation and image}

The participants expressed that the upstanding reputation of the institution and the aim of being recognised both locally and internationally, for instance, in topcalibre research and high-quality teaching and learning, as well as superior service delivery is what attracts their pool of academic talent as indicated by the following participant:

I don't believe we have a specific brand as such; however we are constantly doing our part to ensure that we provide effective and efficient services to our clients, the stakeholders, and ensuring that our staff members are comfortable with that kind of agenda. (Participant 2, male, senior management, doctoral degree, black or African)

Another participant indicated:

In my opinion, we are an internationally recognised university that is largely renowned especially for our research, so that is what I believe is our brand as an Institution. As far as value goes, this institution is extremely committed to offering superior value to all our stakeholders, especially to our academic staff members. (Participant 8, male, executive management, doctoral degree, white) 
Participant 10 further added:

We want to be comparable across the continent; we want to be recognised internationally. (Participant 10, male, middle management, doctoral degree, black or African)

\section{Sub-theme: Organisational culture and identity}

The participants supported the notion that the institution has a relatable, accommodative and attractive organisational culture and identity. The participants expressed that a culture of empowering academic staff to reach their best potential exists within the institution as pointed out by the following participant:

I think specifically and I won't say the campus, but I will rather say the faculty, I think that if you speak to the people that want to come and work here in interviews and stuff, they will tell you that it is because there is a culture in the faculty of empowering people. (Participant 7, female, senior management, doctoral degree, white)

Other participants mentioned the strongly embedded culture of research that makes the institution attractive to academics:

That is why I'm able to stay here for this number of years to see how I can add to the culture of research. (Participant 5, male, executive management, doctoral degree, black or African)

Participant 12 further indicated that there is an organisational identity within the institution, specifically within the faculty the participant worked for, of innovation and entrepreneurship:

Our current brand in the faculty, we are positioning ourselves to become the business and I.T hub of this Institution, so that is, that's sort of what we say as a faculty, so we bring business, I.T and innovation to the table, that is my faculty, the Faculty of Economic Sciences and I.T's value proposition. (Participant 12, male, senior management, doctoral degree, white)

\section{Sub-theme: Corporate social responsibility}

The findings showed that academic staff members are able to draw gratification from being able to contribute to a larger cause through community participation with their institution, according to the participant's answer:

When you work in academia, the assumption is that you want to use your talent in this environment and through your talent you want to contribute to communities, in making them better. (Participant 1, male, executive management, doctoral degree, black or African)

Another participant added:

I think most people would prefer to come to this campus simply because of the contribution they see themselves making. Remember this is more of a rural campus so if you see yourself making a lot of contributions, especially towards the communities that really benefit from the institution, I would see it in that way and then it also gives you the opportunity to engage better as an academic with communities in terms of projects and so on (Participant 6, female, senior management, doctoral degree, black or African)
Participant 11 added that an interest in community involvement is also a factor when identifying strong candidates for employment:

You'll see that the system which is involved in the recruitment and appointment, you'll see that it is done in such a way that we also target the best people who when they come here, they also perform in terms of our requirements, in terms of community engagement. (Participant 11, female, executive management, doctoral degree, black or African)

The participants also mentioned the importance of being able to make a significant contribution not only in teaching and learning as well as research but also to the larger societies which they serve, as indicated by the following participant:

We are recognised for our scholarship in teaching and learning because we really do wonderful things in teaching and learning and we want to be known in terms of our scholarship in teaching and learning and also for the research we do, but not just research for the sake of doing research but doing research relevant to the societies we serve. (Participant 12, male, senior management, doctoral degree, white)

\section{Sub-theme: Strategic vision}

This sub-theme occurred less frequently; however, the participants indicated that strategic vision bears influence on the success of the organisational branding and how well it will be received by stakeholders, especially by academic staff members for the purpose of this research. Some of the participants noted that talent management is a recently embedded component in the institution's strategy, as expressed by the following participants:

At this Institution we realise how important it is to manage the most crucial role players in our core business - our academics which is why our new Institutional strategy even has talent management as one of the main elements. (Participant 1, male, executive management, doctoral degree, black or African)

And:

If you look at our new strategy, I don't know whether you've looked at the strategy, it's the first time I saw academic talent management in our strategy, do you know about it? So that is now a new strategy, I mean we're busy with the implementation but I think I can tell you that it was something I was very pleased about. Now that was previously never in our strategy, so I think for the first time, like your top Vice-chancellor and the likes are saying that this is important. (Participant 7, female, senior management, doctoral degree, white)

\section{Discussion}

The main objective of this study was to explore management perceptions on a higher educational institution as a brand for the attraction of talented academic staff. Six themes were identified as important to the organisational brand of HEIs to attract quality scholars. The themes are reputation and image, organisational culture and identity, strategic vision, corporate social responsibility and work and surrounding environment. 
The theme of work and the surrounding environment was mostly mentioned in this study as all the participants indicated the importance of a conducive and appealing internal and external environment where organisational branding for academic staff members in the HEI is concerned. The findings are in line with Biraghi and Gambetti (2015), who state that universities need to offer competitive levels of work environment that would be conducive to faculty requirements with the aim of gaining faculty loyalty. Cultivating one fragment of academia though ignoring the working settings and enduring career requirements of the other would be a formula for disheartenment and possibly degeneration. Several studies showed that the mobility of academic staff is among others mostly determined by the available resources for research to their disposal (Agarwal \& Ohyama, 2013; De Grip et al., 2010).

Reputation and image was the second most frequently mentioned phenomenon among the participants. Williams and Omar (2014) indicated that prestige and reputation are key for the effective running of HEIs. The participants in particular agreed that the reputation and image of a HEI is pivotal in terms of ensuring an institutional brand that will appeal more to academic staff members (see Raithel \& Schwaiger, 2015). Reputation aids to increase the academic staff's belief in the institutions' reliability and strategies for the future (Covey \& Merrill, 2006). As mentioned by Dolphin and Reed (2011), reputations are a company's treasured assets and replications of itself in the institutional mirror.

The culture and identity of the institution emerged as important factors for its branding. The participants supported the notion that the institution has a relatable, accommodative and attractive organisational culture and identity. Bitzer (2009) contends that even though academics might not take heed of the culture of their institutions in terms of their everyday activities, each institution has a prevalent culture that is not evadable and regulates the manner in which things are carried out at each institution. Genuine and long-lasting academic quality would most probably occur within universities when the enablement and transformation roles reinforce collegiate and revolutionary cultures (Naidoo, 2013).

Corporate social responsibility was the fourth most popular theme among the participants in this study. Dolphin and Reed (2011) maintain that corporate social responsibility initiative is an important attraction factor for employees and contributes to the positive attitudes of all community stakeholders. The participants were in agreement that HEIs can make a more substantial contribution towards uplifting communities through talented staff members. Consequently, higher education can contribute to the well-being of larger communities while offering quality goods (Lamboy, 2011).

Strategic vision was the least mentioned sub-theme under organisational branding among the participants with only a few participants having brought it up. The participants in particular highlighted the importance of including talent management of academics into the strategy. The focus on talent management shows that management has a clear strategic vision in terms of the future standing of the HEI (Balmer et al., 2009). Moreover, a sound vision in terms of talent management can assist HEIs to distinguish itself from competitors (Özdem, 2011).

\section{Practical implications}

From a practical point of view, this research identified the key elements that should form part of an appealing higher education brand that will attract and retain current and future talent. Higher educational managers are encouraged to create an appealing organisational brand and conducive working environment where talented academic staff can flourish and grow. Management should also have the strategic foresight to create a work environment that will contribute to the competitiveness and sustainability of HEIs through its talented academic staff members. This will in turn enhance the reputation of the institution globally as an employer of choice through top-calibre research and highquality teaching and learning as well as superior service delivery.

\section{Limitations and recommendations}

This research had some limitations. The first limitation relates to the limited body of research that exists on organisational branding research within the higher educational domain. Secondly, this research was done in one higher educational institution. As a result, the research cannot be generalised to other HEIs or organisations. Finally, the sample of the research was limited to management perceptions only.

For future research, it is recommended that other higher educational groups such as academics, marketing, human resource management and administrative staff are included to provide a holistic perspective in higher educational branding. This research can also be expanded to other HEIs in South Africa for the purpose of developing a common and compelling higher educational brand that will retain academics to their institutions. Future research can also benefit by adopting a longitudinal approach to detect higher education brand requirements and changes over the long term.

\section{Conclusion}

Branding is a novel and contentious research area in higher education, eliciting scepticism on its possible implementation. Owing to the on-going rivalry, HEIs must accentuate their distinctiveness, which gives rise to a new outlook on HEI, which is the crafting of an international institutional brand. This thought demonstrates that branding is now a contemporary subject in the management of education and it produces a unique export product for the nation. A member of faculty is not likely to take up an offer from a disreputable or less reputable institution merely because of the brand of the institution of learning. Similar to business entities, institutions possess a brand that helps them thrive. A more 
robust brand draws talent into the institution and rallies greater resources. Successful branding should consider the emphasis of internal ideals, ethos and vision and also the outside emphasis on the promotion of the brand.

\section{Acknowledgements Competing interests}

The authors declare that they have no financial or personal relationships that may have inappropriately influenced them in writing this article.

\section{Authors' contributions}

This research is based on the PhD study of M.S. of which E.N.B. was the supervisor and N.E.S. the co-supervisor. M.S. wrote the article and E.N.B. and N.E.S. provided editorial inputs.

\section{References}

Agarwal, R., \& Ohyama, A. (2013). Industry or academia, basic or applied? Career choices and earnings trajectories of scientists. Management Science, 59(4), 950970. https://doi.org/10.1287/mnsc.1120.1582

Alessandri, S.W., Yang, S.-U., \& Kinsey, D.F. (2006). An integrative approach to university visual identity and reputation. Corporate Reputation Review, 9(4), 258270. https://doi.org/10.1057/palgrave. crr.1550033

Amzat, I.H. (2015). Branding higher education institutions: What it takes to be branded. In I.H. Amzat \& B. Yusuf (Eds.), Fast forwarding higher education institutions for global challenges: Perspectives and Approaches (pp. 147-162). Singapore: Springer.

Balmer, J.M.T. (2012). Corporate brand management imperatives: Custodianship, credibility, and calibration. California Management Review, 54, 6-33. https://doi. org/10.1525/cmr.2012.54.3.6

Balmer, J.M.T., Stuart, H., \& Greyser, S.A. (2009). Aligning identity and strategy: Corporate branding at British Airways in the late 20th century. California Corporate branding at British Airways in the late 20th century
Management Review, 51(3), 6-23. https://doi.org/10.2307/41166491

Bernard, H.R., \& Ryan, G.W. (2010). Analyzing qualitative data: Systematic approaches. Thousand Oaks, CA: Sage.

Biraghi, S., \& Gambetti, R.C. (2015). Corporate branding: Where are we? A systematic communication-based inquiry. Journal of Marketing Communications, 21(4), 260283. https://doi.org/10.1080/13527266.2013.768535

Bitzer, E. (Ed.). (2009). Higher Education in South Africa: A scholarly look behind the scenes. Stellenbosch: African Sun Media.

Bowen, G.A. (2009). Document analysis as a qualitative research method. Qualitative Research Journal, 9(2), 27-40. https://doi.org/10.3316/QRJ0902027

Brewer, A., \& Zhao, J. (2010). The impact of a pathway college on reputation and brand awareness for its affiliated university in Sydney. International Journal of Educational Management, 24(1), 34-47. https://doi.org/10.1108/09513541011013033

Bryman, A., \& Bell, E. (2015). Business research methods. (4th edn.). Oxford, UK: Oxford University Press.

Cian, L., \& Cervai, S. (2014). Under the reputation umbrella: An integrative and multidisciplinary review for corporate image, projected image, construed image, organizational identity, and organizational culture. Corporate Communications: An International Journal, 19(2), 182-199. https://doi.org/10.1108/CCIJ-10-2011-0055

Covey, S.M.R., \& Merrill, R.R. (2006). The speed of trust. New York: Free Press.

Creswell, J.W. (2014). Research design: Qualitative, quantitative, and mixed methods approaches. (4th edn.). Thousand Oaks, CA: Sage.

De Grip, A., Fouarge, D., \& Sauermann, J. (2010). What affects international migration of European science and engineering graduates? Economics of
Innovation and New Technology, 19(5), 407-421. https://doi.org/10.1080/ Innovation and New
10438590903434828

Dolphin, R., \& Reed, D. (2011). The fundamentals of corporate communications. Abingdon, OX: Routledge.

Dowling, G., \& Moran, P. (2012). Corporate reputations: Built in or bolted on? California Management Review, 54(2), 25-42. https://doi.org/10.1525/cmr.2012.54.2.25

Flake, D.F. (2015). Image is everything: Corporate branding and religious accommodation in the workplace. University of Pennsylvania Law Review, 163, 699-754.

Helm, S., Liehr-Gobbers, K., \& Storck, C. (2011). Reputation management: Management for professionals [Adobe Digital Editions version]. https://doi. org/10.1007/978-3-642-19266-1

Hemsley-Brown, J., \& Goonawardana, S. (2007). Brand harmonisation in the international higher education market. Journal of Business Research, 60, 942-948. https://doi.org/10.1016/j.jbusres.2007.01.019
Hugo-Burrows, M.M. (1993). Trends and strategies in the marketing of corporate image and identity in a politically-conscious South Africa. In R.L. King (Ed.), Minority marketing: Research perspectives for the 1990s: Proceedings of the 1993 Minority Marketing Congress (pp. 109-113). Switzerland: Springer International Minority Mark
Publishing.

Huisman, J., \& Pausits, A. (Eds.). (2010). Higher Education management and development. Compendium for managers. New York: Waxmann Verlag.

Ivancheva, L., \& Gourova, E. (2011). Challenges for career and mobility of researchers in Europe. Science and Public Policy, 38(3), 185-198. https://doi.org/10.3152/030 234211X12834251302445

Jansen, P.G.W., \& Roodt, G. (Eds.). (2014). Conceptualising and measuring work identity: South-African perspectives and findings. Dordrecht: Springer.

Kuh, G.D., \& Whitt, E.J. (2000). Culture in American colleges and universities. In M.C. Brown (Ed.), Organization \& governance in higher education (5th edn., pp. 160169). Boston: Pearson Custom Publishing.

Lamboy, J.V. (2011). Implications of branding initiatives in higher education among trademarked institutions in California. Doctoral dissertation. Retrieved March 05, 2016, from http://repository.usfca.edu/cgi/viewcontent.cgi?article= $1007 \&$ context $=$ diss

Lane, V.R., \& Scott, S.G. (2007). The neural network model of organisational identification. Organisational Behaviour and Human Decision Processes, 104 175-192. https://doi.org/10.1016/j.obhdp.2007.04.004

Leech, N.L., \& Onwuegbuzie, A.J. (2008). Qualitative data analysis: A compendium of techniques for school psychology research and beyond. School Psychology Quarterly, 23, 587-604. https://doi.org/10.1037/1045-3830.23.4.587

Makondo, L. (2014). Academic attraction and retention trends at a South Africa University. Journal of Social Anthropology, 5(2), 169-177.

Mapesela, M.L.E., \& Strydom, F. (2005, August). Performance management of academic staff in South African higher education: A developmental research project. Conference on Trends in the Management of Human Resource in Higher Education, Paris, France.

Marginson, S., \& Van der Wende, M. (2007). To rank or to be ranked: The impact of global rankings in higher education. Journal of Studies in International Education 11(3/4), 306-329. https://doi.org/10.1177/1028315307303544

Martin, G., Burke, R.J., \& Cooper, C.L. (Eds.). (2011). Corporate reputation: Managing opportunities and threats. Farnham, England: Gower Publishing.

Mayfield, J., Mayfield, M., \& Sharbrough, W.C., III. (2015). Strategic vision and values in top leaders' communications: Motivating language at a higher level. International Journal of Business Communication, 52(1), 97-121. https://doi. org/10.1177/2329488414560282

Naidoo, D. (2013). Reconciling organisational culture and external quality assurance in higher education. Higher Education Management and Policy Volume, 24(2), 8598. https://doi.org/10.1787/hemp-24-5k3w5pdwhm6j

Onah, F.O., \& Anikwe, O.S. (2016). The task of attraction and retention of academic staff in Nigerian Universities. Journal of Management and Strategy, 7(2), 9-20. https://doi.org/10.5430/jms.v7n2p9

Opoku, R., Abratt, R., \& Pitt, L. (2006). Communicating brand personality: Are the websites doing the talking for the top South African business schools? Journal of Brand Management, 14(1), 20-39. https://doi.org/10.1057/palgrave.bm.2550052

Özdem, G. (2011). An analysis of the mission and vision statements on the strategic plans of higher education institutions. Educational Sciences: Theory \& Practise, 11(4), 1887-1894.

Pauzuoliene, J., \& Mauriciene, I. (2012). Organisational culture development in Klaipeda Municipality. Socialiniai Tyrimai, 3(28), 121-132.

Pienaar, C., \& Bester, C.L. (2008). The retention of academics in the early career phase: Empirical research. SA Journal of Human Resource Management, 6(2), 32-41.

Podnar, K. (2014). Corporate communication: A marketing viewpoint. Abingdon, OX: Routledge.

Raithel, S., \& Schwaiger, M. (2015). The effects of corporate reputation perceptions of the general public on shareholder value. Strategic Management Journal, 36, 945956. https://doi.org/10.1002/smj.2248

Sargeant, J. (2012). Qualitative research part II: Participants, analysis, and quality assurance. Journal of Graduate Medical Education, 4(1), 1-3. https://doi. org/10.4300/JGME-D-11-00307.1

Selesho, J.M., \& Naile, I. (2014). Academic staff retention as a human resource factor: University perspective. International Business and Economics Research Journal, 13(2), 295-303. https://doi.org/10.19030/iber.v13i2.8444

Terblanche, N.S. (2015). Customer-based corporate reputation: A study of supermarket customers. In K. Kubacki (Ed.), Ideas in marketing: Finding the new and polishing the old: Proceedings of the 2013 Academy of Marketing Science (AMS) Annual Conference (pp. 207-212). New York: Springer.

Tofallis, C. (2012). A different approach to university rankings. Higher Education, 63(1), 1-18. https://doi.org/10.1007/s10734-011-9417-z

Stolz, I., Hendel, D.D., \& Horn, A.S. (2010). Ranking of rankings: Benchmarking twentyfive higher education ranking systems in Europe. Higher Education, 60(5), 507528. https://doi.org/10.1007/s10734-010-9312-z

Walker, M. (2011). Grounding our vision: Brain research and strategic vision. Independent School, 70(4), 50. https://doi.org/10.1007/s10734-008-9155-z

Wangenge-Ouma, G., Lutomiah, A., \& Langa, P. (2015). Academic incentives for knowledge production in Africa. In N. Cloete, P. Maassen, \& T. Bailey (Eds.) Knowledge production and contradictory functions in African Higher Education, African Minds, Cape Town, South Africa. 
Wæraas, A., \& Solbakk, M.N. (2009). Defining the essence of a university: Lessons from higher education branding. Journal of Higher Education, 57, 449-462.

Whetten, D.A. (2006). Albert and Whetten revisited: Strengthening the concept of organizational identity. Journal of Management Inquiry, 15(3), 219-234. https:// doi.org/10.1177/1056492606291200

Williams, R., \& Van Dyke, N. (2008). Reputation and reality: Ranking major disciplines in Australian universities. Higher Education, 56(1), 1-28. https://doi.org/10.1007/ s10734-007-9086-0
Williams, R.L. Jr., \& Omar, M. (2014). Applying brand management to higher education through the use of the Brand Flux Model - The case of Arcadia University. Journal
of Marketing for Higher Education, 24(2), 222-242. https://doi.org/10.1080/0884 1241.2014.973471

Wood, E., \& Somerville, I. (2008). Public relations and corporate identity. In A. Theaker (Ed.), The public relations handbook (pp. 104-123). Abingdon, OX: Routledge.

Yin, R.K. (2012). Applications of case study research. (3rd edn.). Thousand Oaks, CA: Sage. 